\title{
Expression and Detection of Different Biotype-associated Cell-bound Haemagglutinins of Vibrio cholerae 01
}

\author{
By GUNHILD JONSON, JOAQUIN SANCHEZ \\ AND ANN-MARI SVENNERHOLM* \\ Department of Medical Microbiology, University of Göteborg, S-413 46 Göteborg, Sweden
}

(Received 21 April 1988; revised 26 August 1988; accepted 30 September 1988)

\begin{abstract}
The expression of two cell-bound haemagglutinins, one sensitive to L-fucose (FSHA) and the other to D-mannose (MSHA), on Vibrio cholerae O1 strains of both the classical and the El Tor biotypes was studied by (i) agglutination of chicken and human group $\mathrm{O}$ erythrocytes in the presence of L-fucose or D-mannose, (ii) binding of the bacteria to L-fucose- and D-mannosecoated agarose beads, and (iii) agglutination of the bacteria by 'biotype-specific' antisera. All of the 12 classical strains studied that were isolated before 1979 gave FSHA of human O erythrocytes whereas only 6 of 17 classical strains isolated during recent epidemics expressed FSHA; a few of the classical strains expressed MSHA in addition to FSHA. All the El Tor strains gave MSHA of chicken erythrocytes and one strain also expressed FSHA. Both the cellbound HAs were optimally expressed during the exponential phase of growth; FSHA markedly decreased during the late exponential phase while the MSHA usually persisted into the stationary phase. The expression of FSHA and MSHA correlated very well with the direct binding of vibrios to fucose- and mannose-coated agarose beads, respectively. Antiserum 'specific' for classical vibrios agglutinated classical strains expressing FSHA and also the El Tor strain exhibiting FSHA. Similarly, the anti-El Tor serum agglutinated all El Tor strains and also classical strains expressing MSHA, suggesting that the 'biotype-specific' sera were specific for the biotype-associated cell-bound HAs.
\end{abstract}

\section{INTRODUCTION}

Cholera is caused by two different biotypes, classical and El Tor, of Vibrio cholerae $\mathrm{O}$ group 1, which are further divided into the serotypes Inaba and Ogawa. The two serotypes, which have both shared and non-crossreactive $O$ antigenic determinants (Barua, 1974; Sakazaki et al., 1970), can be differentiated by agglutination with serotype-specific antisera. The different biotypes, on the other hand, are distinguished by a number of non-immunological tests (Barua, 1974).

$V$. cholerae $\mathrm{O} 1$ bacteria agglutinate certain species of erythrocytes and this property correlates with adherence to brush border membranes (Jones \& Freter, 1976). Adhesion to the intestinal epithelium and haemagglutination (HA) by the vibrios may be inhibited by different sugars (Bhattacharjee \& Srivastava, 1978; Jones \& Freter, 1976). There is some evidence that the cellbound HAs expressed by $V$. cholerae are indeed responsible for the adherence of the bacteria to intestinal epithelium (Finn et al., 1987; Guinée et al., 1985; Jones et al., 1976). However, a direct correlation between intestinal attachment and HA expression has not always been seen (Freter \& Jones, 1976; Teppema et al., 1987). At least three different types of cell-bound haemagglutinins (HAs) of $V$. cholerae, one being sensitive to D-mannose (MSHA), another to L-

\footnotetext{
Abbreviations: HA, haemagglutinin (or haemagglutination); FS, fucose-sensitive; MS, mannose-sensitive; FR, fucose-resistant; MR, mannose-resistant; HAI, haemagglutination inhibition; Cl, classical; TSA, Trypticase Soy Agar; TSB, Trypticase Soy Broth; KRT, Krebs-Ringer solution.
} 
fucose (FSHA), and the third being resistant to both sugars (MRFRHA) have been described (Bhattacharjee \& Srivastava, 1978; Hanne \& Finkelstein, 1982; Holmgren et al., 1983); an MRFRHA was recently cloned (van Dongen \& DeGraaf, 1986). In previous studies (Holmgren et al., 1983) we have proposed that the FSHA is associated with the classical biotype and the MSHA with the El Tor biotype, whereas no biotype-association with the MRFRHA has been reported.

For many bacteria the HA property is associated with the possession of adhesive fimbriae on the bacterial surface (Gaastra \& DeGraaf, 1982; Duguid \& Old, 1980). Recently Taylor et al. (1987) convincingly demonstrated the existence of fimbriae on $V$. cholerae. These fimbriae are co-regulated with cholera toxin by the toxR gene. Studies in human volunteers have suggested that the fimbriae are important for the colonization of the small intestine by the vibrios (Herrington et al., 1987). However, it is still unclear whether these fimbriae are associated with HA properties.

The present study was undertaken to characterize the FS and MS cell-bound HAs on a large number of $V$. cholerae $\mathrm{O} 1$ isolates with regard to biotype-association, expression during different culture conditions and reactivity with different species of erythrocytes. Another aim was to evaluate alternative methods for identifying the FSHA and MSHA, respectively.

\section{METHODS}

Bacterial strains. Twenty-nine classical and $19 \mathrm{El}$ Tor $V$. cholerae $\mathrm{O} 1$ strains were used in this study. Their strain designations, biotypes, serotypes and sources are indicated in Table 1. All strains were kept at $-70^{\circ} \mathrm{C}$ in broth containing $20 \%$ (v/v) glycerol.

Culture of bacteria. Colonies from a fresh blood agar plate inoculated with bacteria previously stored at $-70^{\circ} \mathrm{C}$ were suspended in Trypticase Soy Broth (TSB) without glucose, and incubated without shaking at $37^{\circ} \mathrm{C}$ for $16 \mathrm{~h}$. Then $1 \mathrm{ml}$ of the culture was transferred into $40 \mathrm{ml}$ TSB without glucose in a $250 \mathrm{ml}$ flask and cultured with shaking ( 200 r.p.m.) at $37^{\circ} \mathrm{C}$; in some instances bacteria were also cultured at $27^{\circ} \mathrm{C}$. In initial studies, samples from the cultures were collected every hour during the first $8 \mathrm{~h}$ and then at 10 (or 12), 16 and $20 \mathrm{~h}$. Bacterial concentrations were determined according to optical density in a Corning 252 spectrophotometer using a $600 \mathrm{~nm}$ filter, and $1 \mathrm{ml}$ samples of the cultures were centrifuged, washed and resuspended in modified Krebs-Ringer solution (KRT), pH $7 \cdot 4$ (Jones et al., 1976).

Based on the results of the initial kinetic studies, when HA production for various $V$. cholerae strains was followed during $20 \mathrm{~h}$, the bacteria were in subsequent cultures grown until they reached a concentration of $\sim 3-5 \times 10^{9}$ bacteria $\mathrm{ml}^{-1}\left(\mathrm{OD}_{600} \sim 1.0-1 \cdot 5\right)$, which was usually reached within 4-6 $\mathrm{h}$ and corresponded to the mid-exponential phase of the growth curve. The bacteria were then harvested by centrifugation at $8000 \mathrm{~g}$ at $4{ }^{\circ} \mathrm{C}$ for $10 \mathrm{~min}$ and washed and resuspended in KRT buffer to give final concentrations of $10^{10}$ or $5 \times 10^{10}$ bacteria $\mathrm{ml}^{-1}$. In some instances the strains were grown in Syncase medium (Finkelstein et al., 1966) or inoculated on blood agar or Tryptic Soy Agar (TSA) plates and incubated at $37^{\circ} \mathrm{C}$ for $16 \mathrm{~h}$.

Purified antigens. Soluble HA was purified from the supernate of a stationary-phase culture of strain $V$. cholerae O17SR as previously described (Svennerholm et al., 1983). In short, bacteria were cultured in TSB at $37^{\circ} \mathrm{C}$ for $18 \mathrm{~h}$ with shaking. The culture supernate was then subjected to precipitation with $50 \%$ saturated ammonium sulphate, gel filtration on a Sephacryl S-300 column and finally preparative agarose electrophoresis. Purified $V$. cholerae lipopolysaccharide (LPS) was prepared from strain 569B (Inaba) and strain 34 (Ogawa) by hot phenol/water extraction followed by repeated ultracentrifugation (Ørskov et al., 1967). Purified cholera toxin was purchased from List Biological Laboratories.

Antisera. Antisera were prepared in New Zealand White rabbits weighing approximately $3 \mathrm{~kg}$ at the onset of immunization. Four to five injections were given subcutaneously with 2-week intervals; the initial two immunizations were given in Freund's complete adjuvant. The final bleeding was performed 1-2 weeks after the last immunization.

Antiserum 'specific' for El Tor vibrios (anti-El Tor) was produced by immunizing rabbits with $5 \times 10^{9}$ midexponential-phase, cell-bound HA-positive El Tor vibrios (strain X25049, Ogawa) per injection and subsequently absorbing the serum twice with washed and boiled bacteria of the homologous strain and thereafter twice with washed, live mid-exponential-phase classical vibrios (strain T19766, Ogawa). Antiserum 'specific' for classical vibrios (anti-Cl) was prepared by immunizing with mid-exponential-phase cell-bound HA-positive classical vibrios (strain 1451, Ogawa) and subsequently absorbing the serum twice with washed and boiled midexponential-phase bacteria of the homologous strain and thereafter twice with washed, live mid-exponentialphase cell-bound HA-positive El Tor vibrios (strain T20567, Ogawa). The absorptions were performed by mixing 
equal volumes of antiserum and bacterial suspension (final concentration $5 \times 10^{10}$ organisms ml-1) and incubating the mixtures at $37^{\circ} \mathrm{C}$ for $45 \mathrm{~min}$ with rotation. After centrifugation at $11000 \mathrm{~g}$ at $4{ }^{\circ} \mathrm{C}$ for $10 \mathrm{~min}$ the supernates were heat-inactivated at $56^{\circ} \mathrm{C}$ for $30 \mathrm{~min}$ and stored in portions at $-30^{\circ} \mathrm{C}$ until used.

Haemagglutination tests. Haemagglutination of bacteria at an initial concentration of $10^{10}$ organisms ml $^{-1}$, and twofold dilutions thereof in KRT buffer ( $25 \mu \mathrm{l}$ per well) was done in polyvinyl U-bottom microtitration plates (Dynatech Laboratories). To each well was added $25 \mu \mathrm{l}$ of a $1 \%(\mathrm{v} / \mathrm{v})$ erythrocyte suspension in KRT and the titre was recorded, after incubation at room temperature for $30-60 \mathrm{~min}$, as the reciprocal of the highest dilution giving strong HA. All titrations were done in duplicate on the same day and in most instances the experiments were repeated on one or more separate occasions; the results given are the means of all separate titrations for each individual strain. The variation in the HA titre of each strain never exceeded a fourfold difference between the highest and lowest titre.

Slide agglutination was done by mixing $15 \mu$ l of bacteria $\left(1 \times 10^{10}\right.$ organisms $\left.\mathrm{ml}^{-1}\right)$ with $15 \mu \mathrm{l}$ of a $3 \%(\mathrm{v} / \mathrm{v})$ human or chicken erythrocyte suspension in KRT and then slowly rotating the slide for $3 \mathrm{~min}$. HA was recorded as +++ (strong HA), ++ (medium HA) or + (weak HA). Haemagglutination inhibition (HAI) was similarly done by mixing the bacteria with a $0.1 \%(0.006 \mathrm{M})$ solution of D-mannose or L-fucose in KRT buffer for $30 \mathrm{~s}$ before the erythrocyte suspension was added (Holmgren et al., 1983). All analyses were done in duplicate on the same day and in all instances repeated at least twice on separate days.

Binding to sugar-coated agarose beads. Classical and El Tor vibrios were tested for their ability to bind to fucose and mannose covalently attached to agarose beads (agarose- $p$-aminophenyl $\alpha$-L-fucopyranoside and agarose- $p$ aminophenyl $\alpha$-D-mannopyranoside) on a glass slide. Bacteria $\left(10 \mu \mathrm{l}\right.$ of $1 \times 10^{10}$ bacteria ml $\left.^{-1}\right)$ were mixed with $20 \mu$ of the respective bead preparation diluted 1 in 4 in KRT buffer at room temperature. After rotating the slide gently for 1-2 min the binding of the bacteria to the different beads was determined under the phase-contrast microscope at a magnification of $400 x$ and recorded as,+++++ , or + according to the number of bacteria attached to individual beads. When binding was weak incubation was continued for up to 5 or 10 min. All experiments were repeated twice on separate days, and the results given are the means of the separate determinations. The variation in binding for each strain was low, with differences within one unit.

Agglutination with antisera. Fifteen microlitres of anti-El Tor serum, anti-Cl serum and KRT buffer were each mixed with $15 \mu$ l of bacteria $\left(5 \times 10^{10}\right.$ bacteria $\left.\mathrm{ml}^{-1}\right)$ on a glass slide. After gently rotating the slide for $3 \mathrm{~min}$, visible agglutination was recorded as + (strong agglutination), $(+)$ (partial agglutination) or - (no visible agglutination). In cases of + reactions with antisera, threefold dilutions of the sera were tested; the agglutinating titre was determined as the dilution of antiserum giving a + reaction with $5 \times 10^{10}$ bacteria ml $^{-1}$ of the respective strain. Experiments were done in duplicate on the same day and in most instances also repeated on a new batch of bacteria on a separate day. Most results were fully reproducible; some varied with a threefold difference in agglutination titre.

ELISA methods. Anti-El Tor and anti-Cl sera were evaluated for their reactivity with serotype-homologous $V$. cholerae LPS by ELISA (Holmgren \& Svennerholm, 1973). Only sera that, in the concentrations used in the test, lacked significant levels of anti-LPS antibodies, i.e. titres not exceeding that of rabbit preimmune sera, were used. Lack of significant antibody titres in these sera against cholera toxin or soluble HA was also ascertained by ELISA methods (Holmgren \& Svennerholm, 1973; Svennerholm et al., 1983).

Physical and chemical treatment of bacteria. Suspensions of strains 1451 and Cairo 48 (classical), T19479 and X25049 (El Tor) were diluted tenfold in KRT buffer of different $\mathrm{pH}$ values to $2 \times 10^{9}$ bacteria ml $^{-1}$ and incubated at $\mathrm{pH}$ values ranging from 2 to 10 . After incubation at $4{ }^{\circ} \mathrm{C}$ for $30 \mathrm{~min}$ the suspensions were neutralized and the HA titre determined. Bacteria $\left(10^{10}\right.$ organisms $\left.\mathrm{ml}^{-1}\right)$ were also incubated at different temperatures $(20,37,56$ and $80^{\circ} \mathrm{C}$ ) for $30 \mathrm{~min}$ or in $0.005 \mathrm{M}$-EDTA.

\section{RESULTS}

\section{Expression of cell-bound HAs in different media}

The optimal culture conditions for expression of the cell-bound HAs on classical and El Tor $V$. cholerae $\mathrm{O} 1$ were evaluated. Six of the strains representing both biotypes and serotypes were cultured in parallel in different liquid and solid media and their ability to agglutinate different erythrocytes was determined. Human group $\mathrm{O}$ and chicken erythrocytes were used because previous studies have shown that these red blood cells give optimal agglutination by classical and El Tor $V$. cholerae, respectively (Holmgren et al., 1983). The titre of cell-bound HA on classical $V$. cholerae was usually 2-4-fold higher after growth in TSB without glucose than after growth in Syncase, and 8-16-fold higher than that of bacteria grown on TSA or blood agar. The cell-bound HA titre of El Tor vibrios was similar after growth in TSB without glucose and in 
Syncase but was 8-fold higher than after growth on solid media. TSB without glucose was therefore chosen as the culture medium for subsequent studies.

\section{Specificity of cell-bound HAs for different species of erythrocytes}

The specificity of the two biotypes of $V$. cholerae in agglutinating chicken and human $\mathrm{O}$ erythrocytes was evaluated. A number of classical and El Tor strains were titrated in parallel against the two types of erythrocytes. Most (10 of 13) of the classical strains that agglutinated human $O$ erythrocytes also reacted strongly with chicken erythrocytes although titres against human $\mathrm{O}$ erythrocytes were $\geqslant 4$-fold higher for 8 of the $13 \mathrm{HA}$-positive strains. All the El Tor strains agglutinated chicken as well as human $O$ erythrocytes: the HA titre was usually somewhat higher against the chicken cells but a $\geqslant 4$-fold difference was seen only in 4 of the 14 strains.

\section{Sugar specificity of cell-bound HAs}

Strains were tested for HA with human $\mathrm{O}$ and chicken erythrocytes and for HA inhibition with mannose and fucose, respectively. All classical strains isolated before 1979 (except 569B) strongly agglutinated human $\mathrm{O}$ erythrocytes and this HA could in all instances be completely or partly inhibited by $0.1 \%$ fucose (Table $1 a$ ). Classical strains isolated in Bangladesh after 1978 only rarely (6 of 17) agglutinated human $O$ erythrocytes; however, some of the HA-negative strains that were retested after passages on meat extract agar, $\mathrm{pH} 8.5$, agglutinated human $\mathrm{O}$ cells in an FS manner (not shown). The sugar inhibition pattern differed somewhat when chicken erythrocytes were used; e.g. strains $569 \mathrm{~B}$ and Cairo 50 were not inhibited by $0.1 \%$ fucose but were inhibited by $0.1 \%$ mannose, demonstrating the expression of both FSHA and MSHA by these strains (Table $1 a$ ). All the El Tor strains tested agglutinated chicken erythrocytes (Table $1 b$ ). This HA could in all instances be completely or partly inhibited by $0.1 \%$ mannose whereas $0.1 \%$ fucose with one exception had no effect; mannose was often less effective in inhibiting $\mathrm{HA}$ by El Tor vibrios when human erythrocytes were used (Table $1 b$ ).

Identification of cell-bound HAs by binding to sugar-coated beads and agglutination with antisera

The possibility of using a method based on binding of bacteria to agarose beads with covalently coupled mannose or fucose for screening of the two HAs was evaluated by testing 15 classical and $13 \mathrm{El}$ Tor strains in parallel for HAI with the two sugars and for binding to sugarcoated agarose beads (Table 2). All classical strains which exhibited ++ or +++ HA that could be inhibited by fucose, bound to fucose-coated agarose beads. With the exception of strain Cairo 50, which also expressed MSHA, classical strains failed to bind to mannose-coated beads. All the El Tor strains which expressed MSHA, bound strongly to mannose-coated agarose beads and only one strain that also repeatedly exhibited FSHA (Phil 6973) also bound significantly to fucose-coated beads (Table 2).

The different strains were also tested, in parallel with HAI and binding to sugar-coated beads, for agglutination with the 'biotype-specific' anti-Cl and anti-El Tor $V$. cholerae sera, respectively. All but one (569B) of the classical strains were agglutinated by the anti-Cl serum. In some instances the anti-El Tor serum agglutinated the classical strains but usually in lower titre (Table 2). One strain, Cairo 50, that repeatedly expressed MSHA and bound strongly to mannose-coated beads, was strongly agglutinated by the anti-El Tor serum.

The El Tor strains were all agglutinated by the anti-El Tor serum, which had a high titre against most strains, whereas the anti-Cl serum was relatively ineffective (Table 2). Prior incubation of $\mathrm{El}$ Tor T19479 with $1 \%(\mathrm{v} / \mathrm{v})$ mannose repeatedly inhibited agglutination at least fourfold with anti-El Tor antibodies, and preincubation of classical Cairo 48 with fucose partly inhibited agglutination with anti-Cl antibodies (Table 3).

\section{Effect of physical and chemical treatment of HAs}

The effect of incubation at different $\mathrm{pH}$ values and temperatures or in EDTA on the cellbound HA activity was evaluated by comparing HA titres for four different vibrio strains before and after various treatments (Table 4). Cell-bound HA activity of classical as well as El Tor 
Table 1. Haemagglutination by classical and El Tor V. cholerae O1 strains of different species of erythrocytes and inhibition of haemagglutination with monosaccharides

\begin{tabular}{|c|c|c|c|c|c|c|c|c|}
\hline \multirow[b]{3}{*}{ Strain $†$} & \multirow[b]{3}{*}{ Serotype $\ddagger$} & \multirow{3}{*}{$\begin{array}{l}\text { Year of } \\
\text { isolation }\end{array}$} & \multicolumn{6}{|c|}{ Haemagglutination* } \\
\hline & & & \multicolumn{3}{|c|}{$\begin{array}{l}\text { Human } \mathrm{O} \text { erythrocytes } \\
\text { Inhibitor: }\end{array}$} & \multicolumn{3}{|c|}{$\begin{array}{c}\text { Chicken erythrocytes } \\
\text { Inhibitor: }\end{array}$} \\
\hline & & & KRT & Mannose & Fucose & KRT & Mannose & Fucose \\
\hline & \multicolumn{8}{|c|}{ (a) Classical strains } \\
\hline $1^{a}$ & I & $<1970$ & +++ & +++ & - & + & + & - \\
\hline $34^{a}$ & $\mathrm{O}$ & $<1970$ & $+t+$ & +++ & - & + & + & - \\
\hline $35^{a}$ & I & $<1970$ & +++ & +++ & - & ++ & ++ & - \\
\hline $48^{a}$ & I & 1958 & +++ & $++t$ & - & + & + & - \\
\hline $84^{a}$ & I & $<1970$ & +++ & +++ & - & ++ & + & - \\
\hline $86^{a}$ & I & 1941 & +++ & +++ & $(+)$ & ++ & ++ & - \\
\hline $569 \mathrm{~B}^{a}$ & I & $<1970$ & + & $(+)$ & - & $(+)$ & - & $(+)$ \\
\hline $1449^{a}$ & I & 1962 & +++ & +++ & + & $+t$ & ++ & - \\
\hline $1451^{a}$ & O & 1962 & $++t$ & +++ & - & $+t$ & $+t$ & - \\
\hline 57 rough $^{a}$ & 0 & $<1970$ & +++ & $++t$ & - & + & ++ & - \\
\hline Cairo $48^{b}$ & I & 1949 & +++ & +++ & - & +++ & +++ & - \\
\hline Cairo $50^{b}$ & $\mathrm{O}$ & 1949 & +++ & + & - & +++ & - & +++ \\
\hline V63P_c & I & 1979 & +++ & +++ & - & ++ & + & - \\
\hline $\mathrm{T} 19766^{c}$ & O & 1979 & $++t$ & +++ & - & +++ & +++ & - \\
\hline $\mathrm{T} 19767^{c}$ & 0 & 1979 & - & & & - & & \\
\hline $\mathrm{T} 19765^{d}$ & O & 1979 & - & & & - & & \\
\hline $\mathrm{T} 19768^{d}$ & O & 1979 & - & & & - & & \\
\hline $\mathrm{U} 10198^{d}$ & O & 1980 & - & & & - & & \\
\hline $\mathrm{X} 20988^{c}$ & $I$ & 1982 & ++ & + & - & + & - & - \\
\hline$X 20838^{c}$ & I & 1982 & +++ & ++ & - & & NT & \\
\hline$X 29057^{c}$ & I & 1982 & - & & & - & & \\
\hline$X 20752^{c}$ & I & 1982 & - & & & - & & \\
\hline $\mathrm{X} 27495^{c}$ & I & 1982 & - & & & - & & \\
\hline$X 20492^{c}$ & I & 1982 & + & + & - & - & & \\
\hline $\mathrm{X} 19073^{d}$ & I & 1982 & - & & & - & & \\
\hline $\mathrm{X} 19203^{d}$ & I & 1982 & - & & & - & & \\
\hline $\mathrm{X} 23332^{d}$ & I & 1982 & - & & & - & & \\
\hline $\mathrm{X} 24782^{d}$ & I & 1982 & - & & & - & & \\
\hline $\mathrm{X} 28214^{d}$ & I & 1982 & + & + & - & - & & \\
\hline
\end{tabular}

(b) El Tor strains

\begin{tabular}{|c|c|c|c|c|c|c|c|c|}
\hline $1796^{a}$ & 0 & $<1973$ & ++ & - & $+t$ & +++ & - & +++ \\
\hline $1824^{a}$ & o & $<1973$ & +++ & + & ++ & +++ & - & +++ \\
\hline $1836^{a}$ & I & $<1973$ & ++ & - & ++ & +++ & - & $+t+$ \\
\hline $1843^{a}$ & I & $<1973$ & ++ & - & ++ & +++ & - & +++ \\
\hline $1850^{a}$ & I & $<1973$ & ++ & - & ++ & +++ & - & +++ \\
\hline Phil $6973^{e}$ & I & $<1973$ & +++ & ++ & + & +++ & + & ++ \\
\hline $017 \mathrm{SR}^{f}$ & O & $?$ & ++ & - & ++ & +++ & - & +++ \\
\hline $\mathrm{N} 16961^{g}$ & I & $?$ & + & $(+)$ & + & +++ & - & +++ \\
\hline E7946 & 0 & $?$ & + & - & + & +++ & - & +++ \\
\hline T19218 & I & 1979 & ++ & - & ++ & +++ & - & ++ \\
\hline T19479c & I & 1979 & + & - & + & +++ & - & +++ \\
\hline $\mathrm{T} 20567^{\mathrm{c}}$ & $\mathrm{O}$ & 1979 & ++ & - & ++ & +++ & - & +++ \\
\hline T20859 & $\mathrm{O}$ & 1979 & + & $(+)$ & + & +++ & - & +++ \\
\hline $\mathrm{X} 28378^{c}$ & I & 1982 & ++ & + & ++ & +++ & $(+)$ & +++ \\
\hline $\mathrm{X} 20581^{d}$ & I & 1982 & +++ & +++ & +++ & +++ & $(+)$ & +++ \\
\hline $\mathrm{X} 24761^{d}$ & I & 1982 & +++ & ++ & +++ & +++ & $(+)$ & +++ \\
\hline $\mathrm{X} 25049^{d}$ & $\mathrm{O}$ & 1982 & ++ & + & ++ & +++ & $(+)$ & +++ \\
\hline $\mathrm{X} 19215^{d}$ & I & 1982 & +++ & ++ & +++ & +++ & $(+)$ & +++ \\
\hline $\mathrm{X} 19128^{d}$ & $\mathrm{O}$ & 1982 & + & + & + & + & - & + \\
\hline
\end{tabular}

* The results are based on two to four determinations on different days. See Methods for details. NT, Not tested.

+ Strains were obtained from: $a$, Dr H. Smith, Vibrio Reference Laboratory, Philadelphia, PA, USA, and isolated in Dhaka, Bangladesh or Calcutta, India; $b$, National Bacteriological Laboratory, Stockholm, Sweden; $c$, Dr I. Huq, ICDDR, B, Dhaka, Bangladesh; $d$, Dr S. Sanyal, ICDDR, B, Dhaka, Bangladesh; $e$, Statens Seruminstitut, Copenhagen, Denmark; $f$, Dr W. Chaicumpa, Bangkok, Thailand; $g$, Dr M. Levine, Baltimore, USA.

$\ddagger$ I, Inaba; O, Ogawa. 
Table 2. Comparison of haemagglutination $(H A)$ and HA inhibition $(H A I)$ with binding to sugarcoated agarose beads and with agglutination by 'biotype-specific' antisera for demonstration of cell-bound HAs on classical and El Tor V. cholerae OI

\begin{tabular}{|c|c|c|c|c|c|c|}
\hline \multirow[b]{2}{*}{ Strain } & \multirow[b]{2}{*}{ HA } & \multirow[b]{2}{*}{ HAI* } & \multicolumn{2}{|c|}{$\begin{array}{c}\text { Binding to } \\
\text { beads coated with: }\end{array}$} & \multicolumn{2}{|c|}{$\begin{array}{l}\text { Agglutinating } \\
\text { titre of: }\end{array}$} \\
\hline & & & Fucose & Mannose & Anti-Cl & Anti-El To \\
\hline \multicolumn{7}{|l|}{ Classical } \\
\hline 34 & ++ & FSMR & +++ & - & 12 & 3 \\
\hline 35 & +++ & FSMR & ++ & - & 48 & $<6$ \\
\hline $569 \mathrm{~B}$ & + & FSMS & $(+)$ & - & $<6$ & $<3$ \\
\hline 1451 & +++ & FSMR & $+t+$ & - & $\dagger$ & $\dagger$ \\
\hline Cairo 48 & $+t+$ & FSMR & ++ & - & 58 & 3 \\
\hline Cairo 50 & +++ & $\mathbf{F S}(\mathbf{M S})$ & + & +++ & 20 & 90 \\
\hline T19766 & $+t+$ & FSMR & +++ & - & $\dagger$ & $\dagger$ \\
\hline X20988 & ++ & FS(MS) & ++ & - & 58 & 10 \\
\hline X20838 & $+t+$ & FS(MS) & $+t$ & - & 20 & 4 \\
\hline X20492 & + & FSMR & - & - & 12 & 12 \\
\hline X29057 & $(+)$ & & - & - & 6 & $<6$ \\
\hline$\times 28214$ & + & FSMR & + & - & 15 & 3 \\
\hline U10198 & - & & $+\ddagger$ & - & 6 & $<3$ \\
\hline X19073 & - & & + \pm & - & 6 & $<3$ \\
\hline $\mathrm{X} 23332$ & - & & $+\ddagger$ & - & 6 & $<3$ \\
\hline \multicolumn{7}{|l|}{ El Tor } \\
\hline 1824 & +++ & FRMS & - & ++ & 6 & 180 \\
\hline 1836 & +++ & FRMS & - & +++ & 6 & 30 \\
\hline Phil 6973 & +++ & (FS)(MS) & $+t$ & $++t$ & 12 & 60 \\
\hline O17SR & +++ & FRMS & - & ++ & + & + \\
\hline N16961 & +++ & FRMS & - & $+t+$ & $<6$ & 10 \\
\hline E7946 & $+t+$ & FRMS & - & +++ & $<6$ & 20 \\
\hline T19479 & +++ & FRMS & $(+)$ & +++ & $<6$ & 90 \\
\hline $\mathrm{T} 20567$ & +++ & FRMS & - & $++t$ & $<6$ & 90 \\
\hline T20859 & + & FRMS & - & $++t$ & $<6$ & 30 \\
\hline X24761 & $++t$ & FRMS & - & +++ & $<6$ & 10 \\
\hline X25049 & +++ & FRMS & $(+)$ & $+t+$ & 6 & 90 \\
\hline $\mathrm{X} 19215$ & +++ & FRMS & - & +++ & $<6$ & 180 \\
\hline X28378 & +++ & FRMS & - & $+t+$ & $<6$ & 90 \\
\hline
\end{tabular}

* Classical vibrios were agglutinated with human $\mathrm{O}$ erythrocytes and El Tor vibrios with chicken erythrocytes. Brackets indicate partial inhibition.

$\uparrow$ Spontaneous agglutination.

$\ddagger$ Positive after incubation with beads for $10 \mathrm{~min}$.

vibrios was destroyed or reduced by incubation at $\mathrm{pH}$ values below 4 , whereas $\mathrm{HA}$ titres were similar throughout the $\mathrm{pH}$ range 4-10. The classical-associated HA was not, or was only slightly, affected by heating to $56^{\circ} \mathrm{C}$ but was destroyed at $80^{\circ} \mathrm{C}$; this $\mathrm{HA}$ did not agglutinate erythrocytes in the presence of EDTA, suggesting that $\mathrm{Ca}^{2+}$ is necessary for the binding of these bacteria to the erythrocytes (Table 4). The El Tor-associated HA was destroyed by incubation at $56{ }^{\circ} \mathrm{C}$. EDTA had no effect on the HA titre of the El Tor vibrios.

\section{Kinetics of expression of cell-bound HAs}

The kinetics of the expression of cell-bound HAs during culture in TSB without glucose was studied.

For classical vibrios, as exemplified by strain 1451 in Fig. 1, the HA titre was optimal within $4 \mathrm{~h}$, i.e. before maximal bacterial concentration was reached. The HA titre then decreased during the late exponential phase and was usually below the detection limit after $10-12 \mathrm{~h}$ incubation. Similarly, strain 1451 bound strongly to fucose-coated beads only during the early exponential phase; it did not react with mannose-coated beads during any phase of growth (Fig. $1 \mathrm{a}$ ). Agglutination by 'biotype-specific' antisera could not be assessed during the initial $8 \mathrm{~h}$ of 
Table 3. Inhibition by different monosaccharides of $V$. cholerae $O 1$ agglutination with 'biotype-specific' antisera

\begin{tabular}{|c|c|c|c|}
\hline \multirow[b]{2}{*}{ Inhibitor } & & \multicolumn{2}{|c|}{ Agglutinating titre* } \\
\hline & Serum & $\begin{array}{c}\text { El Tor } \\
\text { (T19479) } \\
\text { Anti-El Tor }\end{array}$ & $\begin{array}{c}\text { Classical } \\
\text { (Cairo 48) } \\
\text { Anti-Cl }\end{array}$ \\
\hline $\begin{array}{l}\text { KRT (control) } \\
1 \% \text { L-fucose } \\
1 \% \text { D-mannose }\end{array}$ & & $\begin{array}{l}48 \\
48 \\
12\end{array}$ & $\begin{array}{r}12 \\
<6 \\
9\end{array}$ \\
\hline
\end{tabular}

* The mean agglutinating titres of $10 \mu \mathrm{l}$ of bacteria after preincubation with $10 \mu \mathrm{l}$ of inhibitor for $30 \mathrm{~s}$. Results from two different batches of bacteria varied within one twofold titre unit.

Table 4. Cell-bound HA titre of $V$. cholerae OI after treatment at different temperatures and $p H$ values, or in EDTA

\begin{tabular}{|c|c|c|c|c|}
\hline & $\mathrm{Ha}$ & glutination & dicated e & ocytes* \\
\hline & & sical & & \\
\hline Erythrocytes. & & an $\mathrm{O}$ & & \\
\hline Treatment & 1451 & Cairo 48 & T19479 & X25049 \\
\hline Control: $\mathrm{pH} 7 \cdot 4,4^{\circ} \mathrm{C}$ & 128 & 128 & 64 & 64 \\
\hline Temperature: $20^{\circ} \mathrm{C}$ & 128 & 128 & 64 & 64 \\
\hline $37^{\circ} \mathrm{C}$ & 128 & 128 & 64 & 64 \\
\hline $56^{\circ} \mathrm{C}$ & 128 & 32 & 1 & $<1$ \\
\hline $80^{\circ} \mathrm{C}$ & 1 & $<1$ & $<1$ & $<1$ \\
\hline $\mathrm{pH}: \leq 3$ & 8 & $<8$ & 8 & 32 \\
\hline-4 & 64 & 128 & 64 & 64 \\
\hline 6 & 128 & 128 & 64 & 64 \\
\hline 8 & 128 & 128 & 64 & 64 \\
\hline 9 & 128 & 128 & 64 & 64 \\
\hline 10 & 128 & 128 & 64 & 64 \\
\hline EDTA $(0.005 \mathrm{M})$ & $<1$ & $<1$ & 64 & 64 \\
\hline
\end{tabular}

* The HA titres for $10^{10}$ bacteria $\mathrm{ml}^{-1}$ are shown. The experiments were done in duplicate on the same day. Treatments were repeated with different batches of bacteria. The results given are the means of four titrations. Most results were fully reproducible, but some varied within one titre unit.

the growth curve due to strong autoagglutination of the bacteria during the exponential phase. Samples of bacteria collected after 10 and $16 \mathrm{~h}$ were not agglutinated by either the anti-Cl or the anti-El Tor serum.

For the El Tor vibrios studied there was a parallel increase in cell-bound HA activity and bacterial concentration during the exponential phase of growth. During the late stationary phase the cell-bound HA activity decreased markedly (Fig. $1 b, c$ ) and was usually below the level of detection after $20 \mathrm{~h}$. The El Tor strain Phil 6973, which expressed both MSHA and FSHA in the exponential phase, bound strongly to both mannose-coated and fucose-coated beads in the early exponential phase and retained the mannose-binding ability during the stationary phase. The kinetics of the binding of the El Tor strain T19479 to mannose-coated beads mimicked that of the HA with chicken erythrocytes (Fig. 1c). Agglutination of the vibrios by the anti-El Tor and anti-Cl sera followed the mannose- and fucose-binding ability, respectively, during the initial $12 \mathrm{~h}$. Bacteria collected thereafter were unspecifically agglutinated by both antisera at low level, although no HA was detected. Neither FSHA nor MSHA could be detected in the supernates of the bacterial cultures during any stage of the growth curve, whereas soluble HA (Svennerholm et al., 1983) was produced during the late exponential and stationary phases. 


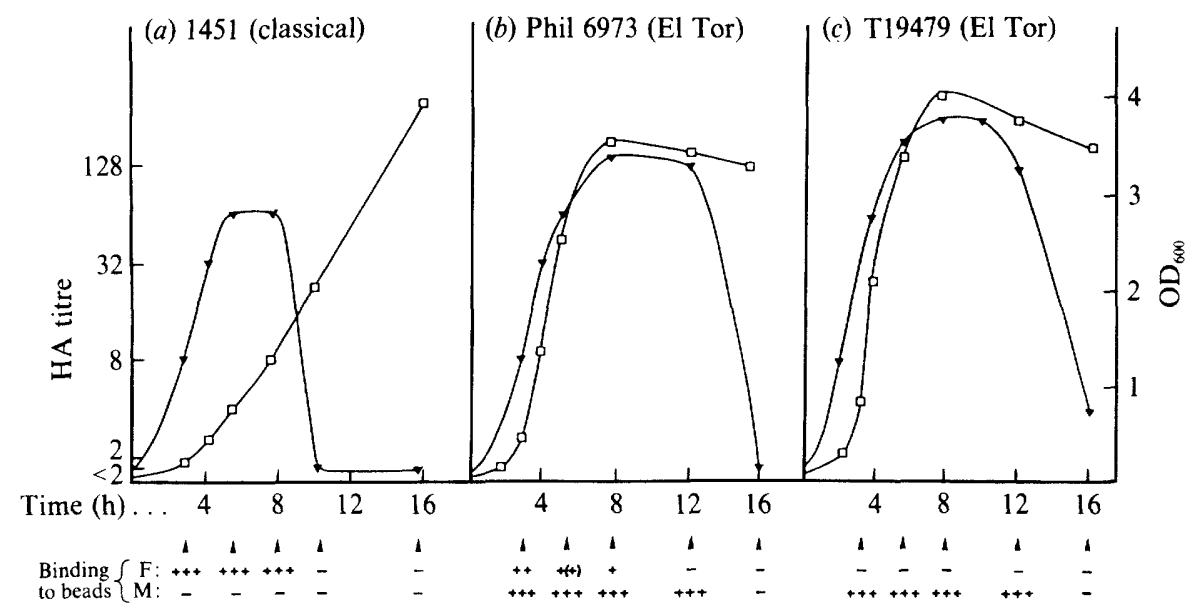

Fig. 1. Kinetics of bacterial growth ( $\square$ ), expression of cell-bound HA activity ( $\nabla$ ), and binding to fucose- (F) and mannose-coated (M) agarose beads, for different $V$. cholerae strains. Bacteria were cultured in TSB without glucose at $37^{\circ} \mathrm{C}$ with shaking (200 r.p.m.). Growth was determined spectrophotometrically. The HA titres were determined after washing the bacteria once and resuspending them in KRT buffer to the original sample volume. HA of strain 1451 was tested using human O erythrocytes and HA of strains Phil 6973 and T19479 using chicken erythrocytes. The binding of bacteria to sugar-coated beads was determined after adjusting to $10^{10}$ organisms ml $^{-1}$; arrows indicate time of sampling. HA titres given are the mean of two independent titrations of each specimen on the same day. HA titres were fully reproducible or varied within one titre unit, and binding results were always fully reproducible.

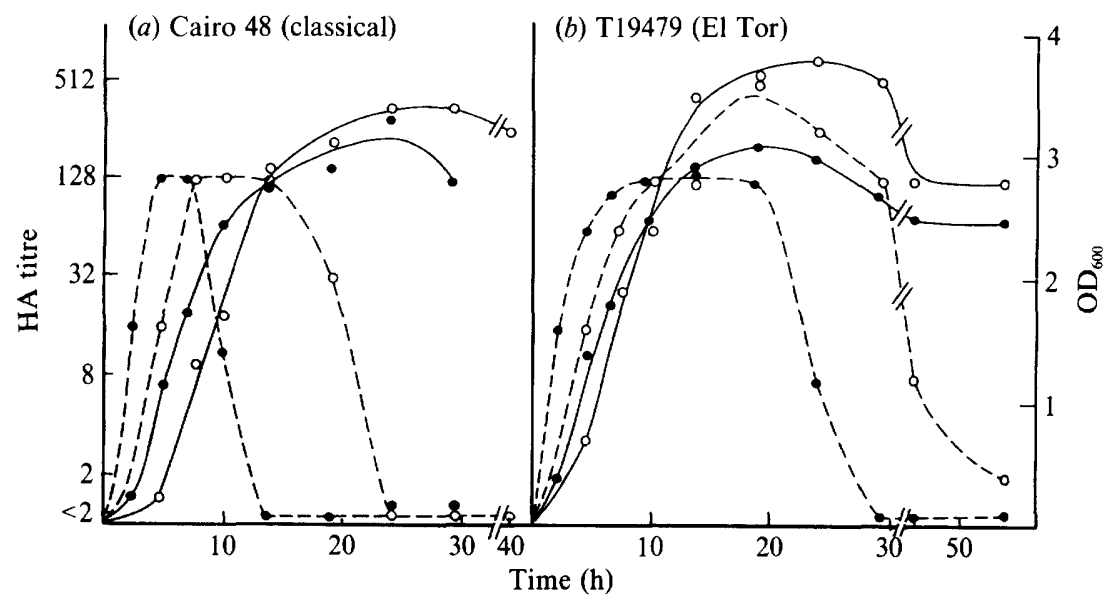

Fig. 2. Kinetics of bacterial growth (solid lines) and of cell-bound HA production (broken lines) by (a) classical Cairo 48 and (b) El Tor T19479 vibrios after culture at $37^{\circ} \mathrm{C}(\mathcal{O})$ and $27^{\circ} \mathrm{C}(\mathrm{O})$ with shaking in TSB without glucose. The $\mathrm{HA}$ titre of classical vibrios was determined using human $\mathrm{O}$ erythrocytes and that of El Tor vibrios using chicken erythrocytes. The results are the mean of HA titrations in duplicate. The experiment was repeated once and the results were in most instances fully reproducible; some titres varied within one titre unit.

The kinetics of the expression of cell-bound $\mathrm{HA}$ at different temperatures was also evaluated. The relatively high HA titres persisted longer after culturing at $27^{\circ} \mathrm{C}$ than at $37^{\circ} \mathrm{C}$ both for the classical strain Cairo 48 and the El Tor strain T19479 tested (Fig. 2). Similar results were observed for the additional two strains tested (not shown). The ratio between the HA and $\mathrm{OD}_{600}$ value for bacteria grown at $27^{\circ} \mathrm{C}$ and $37^{\circ} \mathrm{C}$ did not differ during the exponential phase but was considerably higher after culture at $27^{\circ} \mathrm{C}$ in the stationary phase. 


\section{DISCUSSION}

By using both human $\mathrm{O}$ and chicken erythrocytes in an HAI system with L-fucose and Dmannose as inhibitors, it was possible to detect co-expressed FSHA and MSHA on vibrios in the mid-exponential phase of growth. However, since HAI is sometimes difficult to read, direct binding of the vibrios to a defined receptor or receptor analogue may be preferable or be used as a complementary method. We used a method based on binding of vibrios to agarose beads with covalently bound L-fucose or D-mannose. We showed that binding of $V$. cholerae to these beads is closely related to HA and HAI with specific sugars. The advantages of using the beads include lack of need for fresh biological reagents and a higher specificity for the sugar to be studied. For quantitative studies, however (and for detection of HAs not sensitive to mannose or fucose), HA titration in microtitration plates is superior since it is more sensitive and permits determination of end-point titres.

By absorbing antisera against $V$. cholerae $\mathrm{O} 1$ with biotype-heterologous vibrios of the homologous serotype, sera that agglutinated biotype-homologous vibrios to a considerably higher extent than biotype-heterologous vibrios were obtained, suggesting the presence of biotype-specific antigens. The possibility of inhibiting at all the biotype-homologous serum aggutination of El Tor vibrios by addition of mannose, and that of classical vibrios by fucose, suggests that the sera were at least partly directed against the respective cell-bound HA.

In contrast to the MSHA that is expressed through to the stationary phase, the FSHA activity disappeared quite abruptly in the late exponential phase. Possible explanations for this difference may be that FSHA is expressed only on an early population of bacteria (phase variation), as observed for Escherichia coli fimbriae (Nowicki et al., 1986). An alternative explanation is that FSHA is more sensitive to one or more substances, possibly proteolytic enzymes, formed during in vitro culture. Although we did not identify any FSHA activity in any of the culture supernates tested, either directly or in HAI studies, we cannot exclude the possibility that the outer-membrane structure responsible for binding to erythrocytes is shed from the bacteria with simultaneous loss of HA activity. Alternatively, the FSHA may be masked by a surface structure expressed during the late exponential phase.

An interesting observation during the kinetic experiments was that strain 1451 was strongly autoagglutinating in KRT buffer as long as FSHA was expressed on the bacterial surface. Several other $V$. cholerae strains, e.g. Phil 6973, O17SR, 1449 and T19766, autoagglutinated in the early exponential phase. A possible explanation for this agglutination is the presence of hydrophobic adhesins or fimbriae on the vibrio surface as described for the classical $V$. cholerae strain 395 (Taylor et al., 1987). A high degree of hydrophobicity during exponential growth has been described for vibrios of both biotypes (Kabir \& Ali, 1983). We have observed that $V$. cholerae often have a tendency to autoaggregate after being kept for long periods in deep agar. This may suggest a change in the surface structure, e.g. length of polysaccharide chains, resulting in a better exposure of the FSHA. This phenomenon may explain why all the old classical strains isolated before 1973, which had been subcultured in deep agar before this study was initiated, exhibited greater FSHA than the fresh isolates.

The possibility that either the MS or the FS cell-bound HA may correspond to or be associated with the recently described tox $R$-gene-regulated pili (Taylor et al., 1987) is less likely. In contrast to observations for the pili, we did not find a clear correlation between the expression of the two HAs and the levels of cholera toxin (not shown). Furthermore, the piliated $V$. cholerae strain used by Taylor et al. (1987) bound to fucose-beads but not to mannose-beads after culturing under conditions favouring production of pili, suggesting that MSHA does not involve the fimbrial structure. One way to determine whether FSHA is related to the pili would be to find out whether pili-negative mutants (Taylor et al., 1987) still bind to fucose-beads.

This study shows that $V$. cholerae FS and MSHAs are mainly biotype-associated but can be expressed and detected on both biotypes by HAI, by binding to sugar-coated agarose beads or by antibodies. The expression of FSHA is growth-phase dependent and difficult to demonstrate on many strains.

Although studies in different laboratories suggest that expression of FSHA or MSHA could promote bacterial adhesion in vitro, it remains to be seen whether any of these HAs are operating 
as adhesins during infection. Since both the FSHA and the MSHA are immunogens, passive protection studies in experimental animals may help to determine whether antibodies to these structures play a role in protection against cholera.

This study was supported by grants from the Swedish Medical Research Council (grant 16X-3382) and the Faculty of Medicine, University of Göteborg, Göteborg.

\section{REFERE NCES}

BARUA, D. (1974). Laboratory diagnosis of cholera. In Cholera, pp. 85-126. Edited by D. Barua \& W. Burrows. Philadelphia: Saunders.

Bhattacharjee, J. W. \& Srivastava, B. S. (1978). Mannose-sensitive haemagglutinins in adherence of Vibrio cholerae El Tor to intestine. Journal of General Microbiology 108, 407-410.

van Dongen, W. M. A. M. \& DeGraAf, F. K. (1986). Molecular cloning of a gene coding for a Vibrio cholerae haemagglutinin. Journal of General Microbiology 132, 2225-2234.

Duguid, J. \& OLD, D. (1980). Adhesive properties of Enterobacteriaceae. In Bacterial Adherence, pp. 185217. Edited by E. Beachey. London: Chapman \& Hall.

Finkelstein, R. A., Atthasampunna, P., ChulasaMaya, M. \& Charunmethee, P. (1966). Pathogenesis of experimental cholera. Biologic activities of purified procholeragen A. Journal of Immunology 96, 440-449.

FinN, T. M., Reiser, J., Germanier, R. \& CRYz, S. J., $J_{R}$ (1987). Cell-associated hemagglutinin-deficient mutant of Vibrio cholerae. Infection and Immunity 55 , 942-946.

Freter, R. \& Jones, G. W. (1976). Adhesive properties of Vibrio cholerae: nature of interaction with intact mucosal surfaces. Infection and Immunity 14, 246-256.

GaAstra, W. \& DeGraAF, F. K. (1982). Host-specific fimbrial adhesins of noninvasive enterotoxigenic Escherichia coli strains. Microbiological Reviews 46, 129-161.

Guinée, P. A. M., Jansen, W. H. \& Peters, P. W. J. (1985). Vibrio cholerae infection and acquired immunity in an adult rabbit model. Zentralblatt für Bakteriologie und Hygiene A259, 118-131.

HANNE, F. \& Finkelstein, R. A. (1982). Characterization and distribution of the hemagglutinins produced by Vibrio cholerae. Infection and Immunity 36, 209214.

Herrington, D. A., Tacket, C. O., Losonsky, G. A., Mekalanos, J. J., TAYloR, R. K. \& LeVINE, M. M. (1987). Tcp A pili are a colonization factor of Vibrio cholerae O1. Abstracts of the 23rd Joint Conference on Cholera of the US-Japan Cooperative Medical Science Program, p.47.

Holmgren, J. \& Svennerholm, A.-M. (1973). Enzyme-linked immunosorbent assays for cholera serology. Infection and Immunity 7, 759-763.
Holmgren, J., SVennerholm, A.-M. \& Lindblad, M. (1983). Receptor-like glycocompounds in human milk that inhibit classical and el Tor Vibrio cholerae cell adherence (hemagglutination). Infection and Immunity 39, 147-154.

Jones, G. W., Abrams, G. D. \& Freter, R. (1976). Adhesive properties of Vibrio cholerae: adhesion to isolated rabbit brush border membranes and hemagglutinating activity. Infection and Immunity 14, 232-239.

JONES, G. W. \& FreTER, R. (1976). Adhesive properties of Vibrio cholerae: nature of the interaction with isolated rabbit brush border membrane and human erythrocytes. Infection and Immunity 14, 240-245.

KABIR, S. \& ALI, S. (1983). Characterization of surface properties of Vibrio cholerae. Infection and Immunity 39, 1048-1058.

Nowicki, B., Vuopio-Varkila, J., VilJanen, P., Korhonen, T. K. \& MÄKELÄ, P. H. (1986). Fimbrial phase variation and systemic $E$. coli infection studied in the mouse peritonitis model. Microbial Pathogenesis 1, 335-347.

ØRSKOV, F., ØRSKOV, I., JANN, B., MÜLLER-SEITZ, E. \& WESTPHAL, O. (1967). Immunochemistry of Escherichia coli $\mathrm{O}$ antigens. Acta pathologica et microbiologica scandinavica B71, 339-358.

Sakazaki, R., Tamuar, K., Gomex, C. Z. \& Sen, R. (1970). Serological studies on the cholera group of vibrios. Japanese Journal of Medical Science and Biology 23, 13-20.

SVENNERHOLM, A.-M., JoNSON STRÖMBERG, G. \& Holmgren, J. (1983). Purification of Vibrio cholerae soluble hemagglutinin and development of enzymelinked immunosorbent assays for antigen and antibody quantitations. Infection and Immunity 41, 237243.

Taylor, R. K., Miller, V. L., Furlong, D. B. \& MeKalanos, J. J. (1987). Use of phoA gene fusions to identify a pilus colonization factor coordinately regulated with cholera toxin. Proceedings of the National Academy of Sciences of the United States of America 84, 2833-2837.

Teppema, J. S., Guinée, P. A. M., Ibrahim, A. A., PAQuer, M. \& Ruitenberg, E. J. (1987). In vivo adherence and colonization of Vibrio cholerae strains that differ in hemagglutinating activity and motility. Infection and Immunity 55, 2093-2102. 